\title{
Behavioral effects of corticotropin-releasing factor: localization and characterization of central effects
}

\author{
D.D. Krahn ${ }^{1}$, B.A. Gosnell ${ }^{1}$, A.S. Levine ${ }^{2}$ and J.E. Morley ${ }^{3}$ \\ 'Eating Disorders Center, Department of Psychiatry, University of Michigan, Ann Arbor, MI 48109-0116 (U.S.A.), \\ ${ }^{2}$ Neuroendocrine Research Laboratory, VA Medical Center, Minneapolis, MN (U.S.A.) and ${ }^{3}$ Geriatrir Research, \\ Education and Clinical Center, VA Medical Center, Sepulveda, CA (U.S.A.)
}

(Accepted 18 August 1987)

Key words: Corticotropin-releasing factor (CRF); Hypothalamus; Grooming behavior; Behavior-CRF

\begin{abstract}
Corticotropin-releasing factor (CRF) has potent behavioral effects when administered intracerebroventricularly io rats. 6 is: and its receptors are found in an uneven distribution in the brain. In an effort to localize the site of the anorectic effect of CRF, exngenous CRF or saline was injected into camnuias directed toward the paraventricular hypnthalamic nucleus (PVN), lateral hypothalamus, ventromedial hypothalamus, globus pallidus, or striatum of rats. CRF decreased food intake only when injected into the PVN. In subsequent experiments PVN injections of CRF were shown to (1) increase grooming and movement; (2) not induce a conditioned taste aversion to saccharin in a single bottle test; and (3) inhibit the increase in feeding induced by injections of norepinephrine into the PVN. These results suggest that CRF induces not only anorexia, but also increased movement and grooming by action in the PVN.
\end{abstract}

\section{INTRODUCTION}

A 41 amino acid peptide which fulfills the criteria for physiological corticotropin-releasing factor (CRF) was characterized in 1981 by Spiess et al. ${ }^{19}$. This discovery allowed two lines of research to proceeed. First, the behavioral effects of CRF administered into the lateral ventricles of rats could be studied. Rats given CRF intracerebroventricularly (i.c.v.) have been reported to groom more ${ }^{4.14}$, move and rear less in the open field ${ }^{20}$, and to move more in a familiar environment $t^{4.14 .20}$. These behaviors have been reported as being similar to those behaviors seen in rats exposed to stressors.

The second line of research made possible by the discovery of CRF was the use of immunohistochemical and radioimmunoassay techniques in localizing

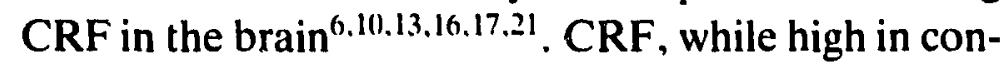
centration in the median eminence as would be expected for a releasing factor, is also found in an un- even distribution throughout many intra- and extrahypothalamic nuclei. Thus, CRF, given via the relatively non-specific technique of intraventricular injection, changes consummatory behaviors including feeding and grooming in the rat. In the experiments reported here, we examined the effects on eating and other behaviors of CRF administered via the more specific method of local, intracerebral injection.

Our initial study focused on food intake alone. We selected 5 areas for testing with local injections of CRF. These areas have been shown by lesioning and/or electrical stimulation techniques to be important in food iniake. They include the paraventricular nucleus of the hypothalamus (PVN), the lateral hypothalamus $(\mathrm{LH})$, the ventromedial nucleus of the hypothalamus (VMH), the globus pallidus (GP) and the striatum $(S)^{15}$. When this initial study showed that CRF significantly suppressed food intake when administered into the PVN but not when injected in the other nuclei, we performed 3 more experiments

Correspondence: D.D. Krahn, Eating Disorders Center. Department of Psychiatry. University of Michigan, Ann Arbor. M1 48109. 0116. U.S.A. 
aimed at better characierizing the effects of CRF in the PVN. The first of these experiments was designed to determine the behavioral specificity of CRF administered into the PVN. As norepinephrine has been well characterized to increase feeding following local injection into the PVN ${ }^{\prime \prime}$, we next determined the effects of CRF administered in the PVN on feeding induced by norepinephrine (NE) administered in the PVN. CRF has been shown to produce a conditioned taste aversion when administered into the lateral ventricle ${ }^{8}$. We therefore also examined whether CRF would produce a taste aversion after injection into the PVN.

\section{MATERIALS AND METHODS}

In the first experiment, 33 male Sprague-Dawley rats $(250-300 \mathrm{~g})$ were housed individually in a $12 \mathrm{~h}$ light/12 $\mathrm{h}$ dark, temperature-controlled environment. Stainless-steel cannulas (23 gauge) were stereotaxically implanted into the following brain areas: PVN, VMH, LH, GP and S. Coordinates used for implantation are shown in Table $\mathrm{I}$.

At least 5 days were allowed for recovery. Then, after $24 \mathrm{~h}$ of food deprivation, rats were admin istered ovine CRF ( $0.5 \mu \mathrm{g}$; Peninsula) or normal saline in a $0.5 \mu \mathrm{l}$ volume via the indwelling cannulas. Four days later, after a similar deprivation, rats received the treatment not received on the first day. Drug treatments were counterbalanced to control for trial effects.

Injections were made with a 30-gauge cannula which extended $0.5 \mathrm{~mm}$ below the end of the guide cannula. The injection was given over a $30-5$ period using a hand-held microsyringe and the injection can- nula was left in place an additional $10 \mathrm{~s}$. Immediately after injection, each rat was returned to its home cage along with two preweighed pellets of Purina rat chow. Intake was calculated by weighing 1 and $2 \mathrm{~h}$ after injection. After testing was completed, animals were sacrificed by intracardiac perfusion with formalin. Brains were fixed with formalin-10\% sucrose solution and stained with Cresyl violet. Cannula placement was verified by comparison with the atlas of the rat brain by Pellegrino et al. ${ }^{18}$. Data from rats with incorrectly placed cannulas were discarded. Data were analyzed by ANOVA, followed by repeated measures $t$-tests to compare intakes after saline vs CRF at each site at 1 and $2 \mathrm{~h}$.

In the second experiment, 12 male Sprague-Dawley rats were implanted with cannulas in the PVN a: in the first experiment. Following a 5-day recovery period, the animals were injected with $0.5 \mu \mathrm{g}$ of CRF or saline as in the first experiment. Testing was done in home cages at $16.00 \mathrm{~h}$ with rats in the two following conditions: $24 \mathrm{~h}$ food deprivation, and no food deprivation. In a counterbalanced design, each animal received saline and CRF treatments in both conditions; thus receiving 4 trials spaced by at least 3 days. After injection, each animal was observed in its home cage by an experienced rater blind to the drug treatment, as described previously ${ }^{14}$. Each animal was observed once per minute. Observed behaviors were classified into one of 6 mutually exclusive categories: grooming, moving, resting, eating, drinking, or rearing. Food intake was measured as in the first experiment. The behavioral data were analyzed with a 2-factor ANOVA (CRF treatment $x$ previous deprivation). Food intake data in the deprived condition were analyzed with $t$-tests for repeated measures. Intake in

\section{TABLE I}

Coordinates used for local cannula placements

\begin{tabular}{|c|c|c|c|c|}
\hline Nucleus & Incisor $^{a}$ & $A P^{b}$ & Laterai & Vertical \\
\hline Striatum & $+5.0 \mathrm{~mm}^{\mathrm{a}}$ & $+2.0 \mathrm{~mm}$ & $+3.0 \mathrm{~mm}$ & $-4.5 \mathrm{~mm}^{\mathrm{c}}$ \\
\hline Paraventricular nucleus & $+3.1 \mathrm{~mm}$ & $-0.2 \mathrm{~mm}$ & $+0.4 \mathrm{~mm}$ & $-7.5 \mathrm{~mm}^{\mathrm{d}}$ \\
\hline Ventromedial hypothalamus & $+5.0 \mathrm{~mm}$ & $0.0 \mathrm{~mm}$ & $+0.6 \mathrm{~mm}$ & $-9.0 \mathrm{~mm}^{\mathrm{d}}$ \\
\hline Lateral hypothalamus & $-3.0 \mathrm{~mm}$ & $-2.4 \mathrm{~mm}$ & $+1.9 \mathrm{~mm}$ & $-0.8 \mathrm{~mm}^{\mathrm{d}}$ \\
\hline Globus pallidus & $+5.0 \mathrm{~min}$ & $+0.7 \mathrm{~mm}$ & $+3.1 \mathrm{~mm}$ & $-5.1 \mathrm{~mm}^{\mathrm{c}}$ \\
\hline
\end{tabular}

a Above ear bars.

b From bregma.

c From dura.

d From skull. 
the non-deprived condition was minimal and therefore was not analyzed.

In a third experiment, 12 male Sprague-Dawley rats with PVN cannulas were treated as in the first two experiments with the exception that they were not food-deprived prior to testing. Animals received injections of CRF ( $0.5 \mathrm{mg}$ in a $0.25-\mu \mathrm{l}$ volume) or normal saline (NS) followed immediately by injections of $50 \mathrm{nmol} / 0.25 \mu \mathrm{l}$ of NE (Sigma, St. Louis, $\mathrm{MO}$ ) or acidified normal saline (NSA, pH 3). Each rat was tested 3 times, with all animals receiving the following treatments: NS/NSA, NS/NE, and CRF/ NE. Some of these animals were also tested with a lower dose of NE (with NS and CRF); these data are not presented here. Rats that failed to eat $0.5 \mathrm{~g}$ of food in the first hour after the NS/NE treatment were excluded from further analysis. Data were analyzed initially with a one-way ANOVA; the least significant difference procedure was then used to evaluate pairwise comparisons.

A fourth experiment used 12 male Sprague-Dawley rats, each with a cannula in the PVN. For 4 days following surgery, rats were given ad libitum food and water. Following this recovery period, rats were trained to drink water in a defined period by restricting access to water to only $12.00-13.00 \mathrm{~h}$ each day for one week. The next day, rats were given a preweighed amount of $0.15 \%$ sodium saccharin solution in their usual water bottles from $12.00-13.00 \mathrm{~h}$. Immediately after $30 \mathrm{~min}$ of exposure to saccharin, a $0.5-\mu l$ injection into the PVN of CRF $(0.5 \mu \mathrm{g}$; a dose that suppressed food intake in the previous experiments) or NS was administered. Amount consumed was determined by weight. After a 1-day return to the $1 \mathrm{~h} /$ day access to water regimen, the animals were re-exposed to saccharin in the same manner as previously described for $30 \mathrm{~min}$. This methodologv is essentially the same as had been used in our laboratory previously to demonstrate cunditioned taste aversion to saccharin after i.c.v. administration of CRF ${ }^{8}$. Saccharin solution intakes on the second day were compared with $i$-tests for independent groups.

\section{RESULTS}

Fig. 1 shows the results of the first experiment, in which food intake was measured after injections of CRF into 5 brain areas. The only area in which CRF

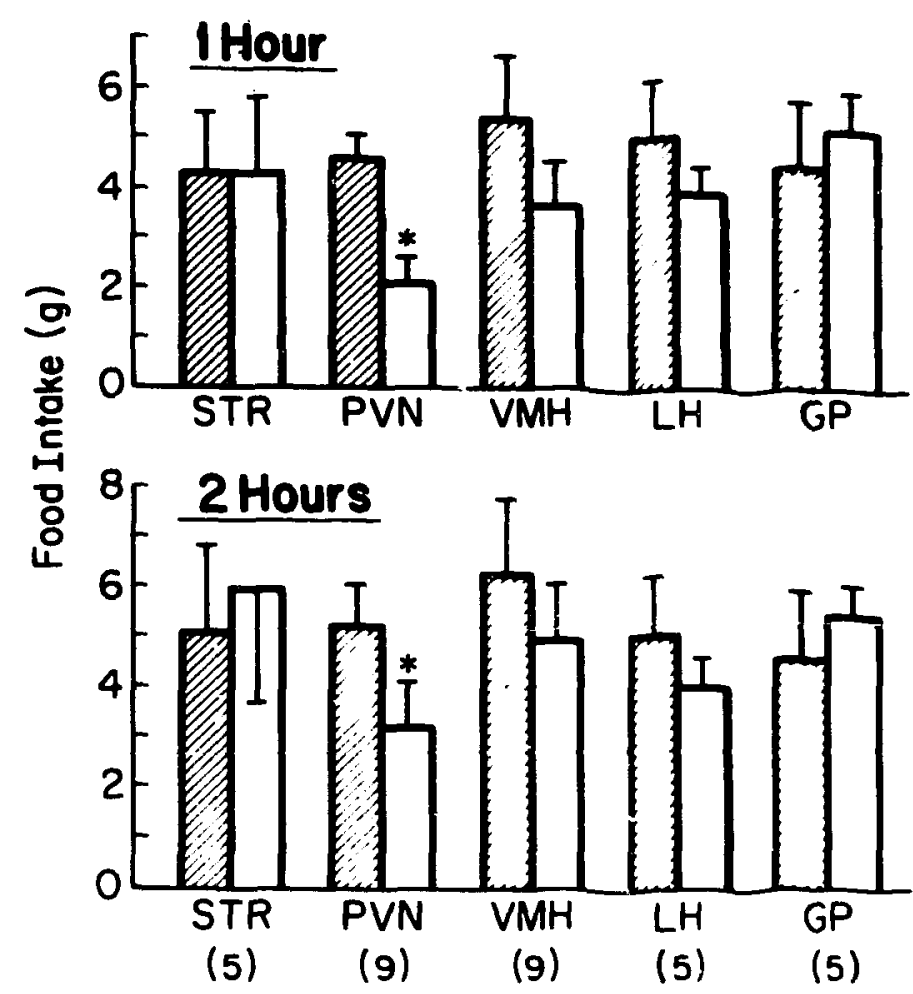

Fig. 1. Food intake (means \pm S.E.M.) after injections of saline (hatched bars) or CRF ( $0.5 \mu \mathrm{g}$. open bars) into the striatum (STR), paraventricular hypothalamic nucleus (PVN), ventromedial hypothalamus (VMH). lateral hypothalamus (LH) or globus paliidus (GP). Rats were food-deprived for $24 \mathrm{~h}$ prior to testing, and each rat was tested with both saline and CRF. Numbers at bottom indicate group sizes; ${ }^{*}$ indicates a significant difference from the corresponding saline condition $(P<$ $0.05)$.

$(0.5 \mu \mathrm{g})$ had a significant effect on food intake was the PVN. At $1 \mathrm{~h}$, the CRF-treated rats with cannulas in the $P^{\prime}$ ' $N$ showed a significant suppression of mean food intake of $62.9 \%\left(t(8)=4.21^{\prime}, P<0.05\right)$. At $2 \mathrm{~h}$. mean intake in these rats was reduced by $32.9 \%(t(8)$

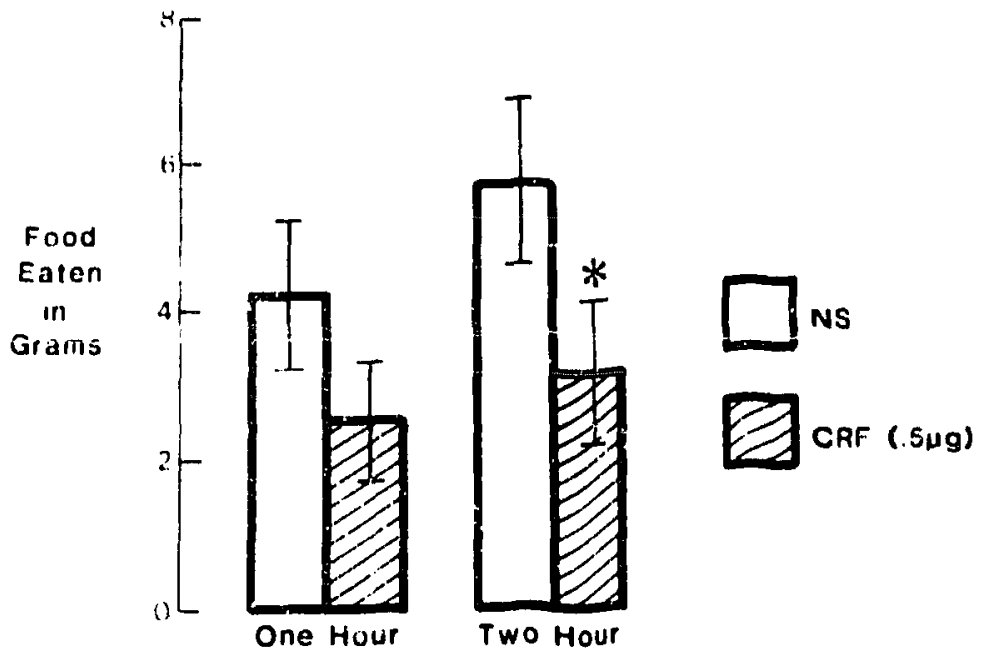

Fig. 2. Foud intake (means \pm S.E.M.) of rats in Expt. 2 given CRF $(0.5 \mu \mathrm{g} / 0.5 \mu \mathrm{l}$, open bars) or saline (0.5 $\mu \mathrm{l}$, hatched bars) in the PVN after $2+\mathrm{h}$ food deprivation. * Indicates a significant decrease in food intake $(P<0.05$, repeated measures $t$-tests, $n$ $=12$ ). 


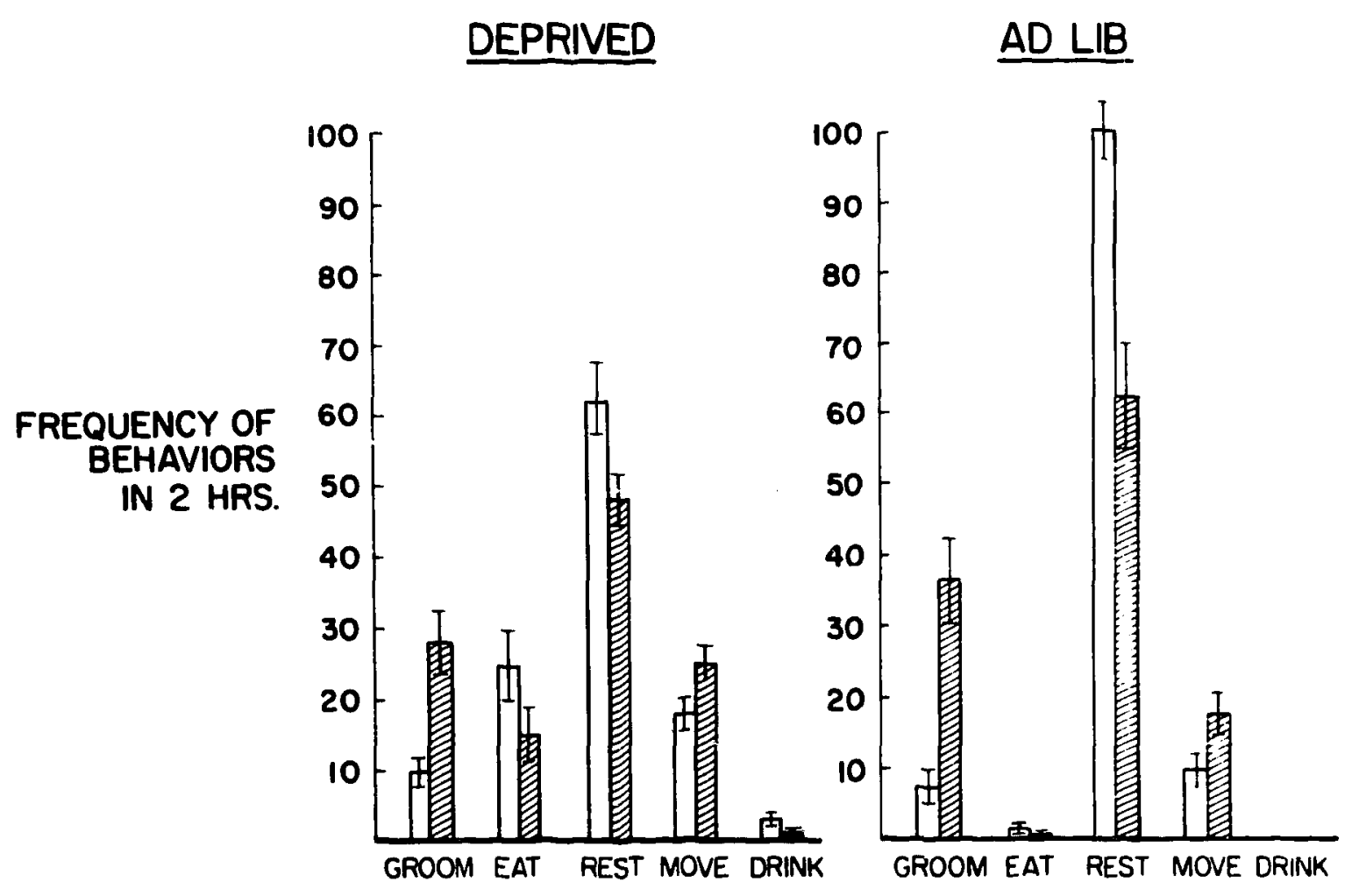

Fig. 3. Frequencies of 5 behaviors (means \pm S.E.M.) observed in $2 \mathrm{~h}$ after injection into the PVN of CRF $(0.5 \mu \mathrm{g} / 0.5 \mu \mathrm{l})$ or saline $(0.5$ $\mu \mathrm{l}$ ) in rats previously food-deprived or fed ad libitum. For each behavior, clear bars indicate frequency of behavior after saline injection and hatched bars indicate frequency of behavior after CRF injection. Rearing frequency is not shown as this was an extremely rare behavior.

\section{$=3.63, P<0.05)$.}

The second experiment was designed to demonstrate the effects of CRF administered into the PVN on behaviors besides feeding in different states of starvation. As shown in Fig. 2, CRF (0.5 $\mu \mathrm{g})$ administered into the PVN in the food-deprived condition decreased food intake significantly at $2 \mathrm{~h}(t(11)=$ 4.0, $P<0.05)$. At $1 \mathrm{~h}$, this decreased approached significance $(t(11)=2.17, P=0.053$, repeated measures $t$-test, two-tailed).

Fig. 3 shows the frequency of behaviors observed in 4 conditions: no deprivation, normal saline; no deprivation, CRF (0.5 $\mu \mathrm{g}$ in PVN); $24 \mathrm{~h}$ food deprivation, normal saline; and $24 \mathrm{~h}$ food deprivation, CRF $(0.5 \mu \mathrm{g}$ in PVN). Two-way analysis of variance indicated a significant effect of CRF on grooming as well as a significant interaction of deprivation with CRF treatment $\left(F_{1.11}=24.67\right.$ and 5.45, respectively, $P<$ 0.05). As expected, both CRF treatment and deprivation state significantly affected frequency of eating behaviors $\left(F_{1.11}=9.19\right.$ and 23.54 , respectively, $P<$ 0.05). The deprivation $\times$ CRF interaction was also significant $\left(F_{1,11}=9.67, P<0.05\right)$. The frequency of observed drinking behavior was affected in a manner similar to that of feeding behavior, with significant effe is $_{\mathrm{s}}$ of CRF and deprivation state and a significant interaction.

The frequincies of behaviors classified as movement and resting were generally affected in a reciprocal manner by both CRF and deprivation state. For resting behavior, there were significant effects of

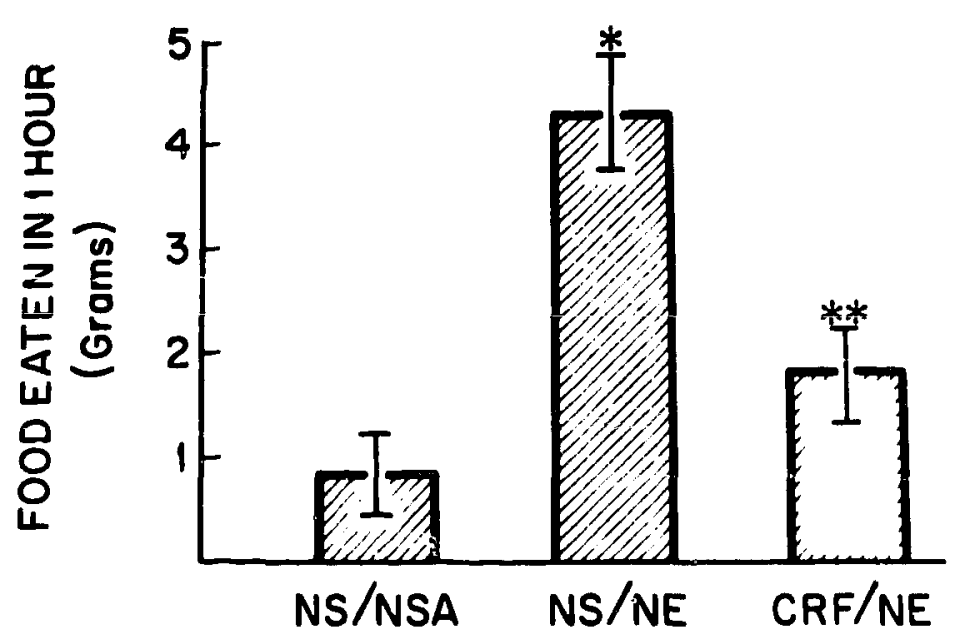

Fig. 4. One-hour food intake (means \pm S.E.M.) of 12 rats in a repeated measures design after treatment with: (1) normal saline and acidified normal saline (NS/NSA); (2) normal saline + norepinephrine (50 nmol/0.25 $\mu \mathrm{l}$; NS/NE); or (3) CRF (0.5 $\mu \mathrm{g} / 0.25 \mu \mathrm{l})$ and NE (CRF/NE). ${ }^{*}$ Indicates a significant increase above the NS/NSA group. ** Indicates a significant difference from the NS/NE group $(P<0.05$, least significant difference procedure, two-tailed). 


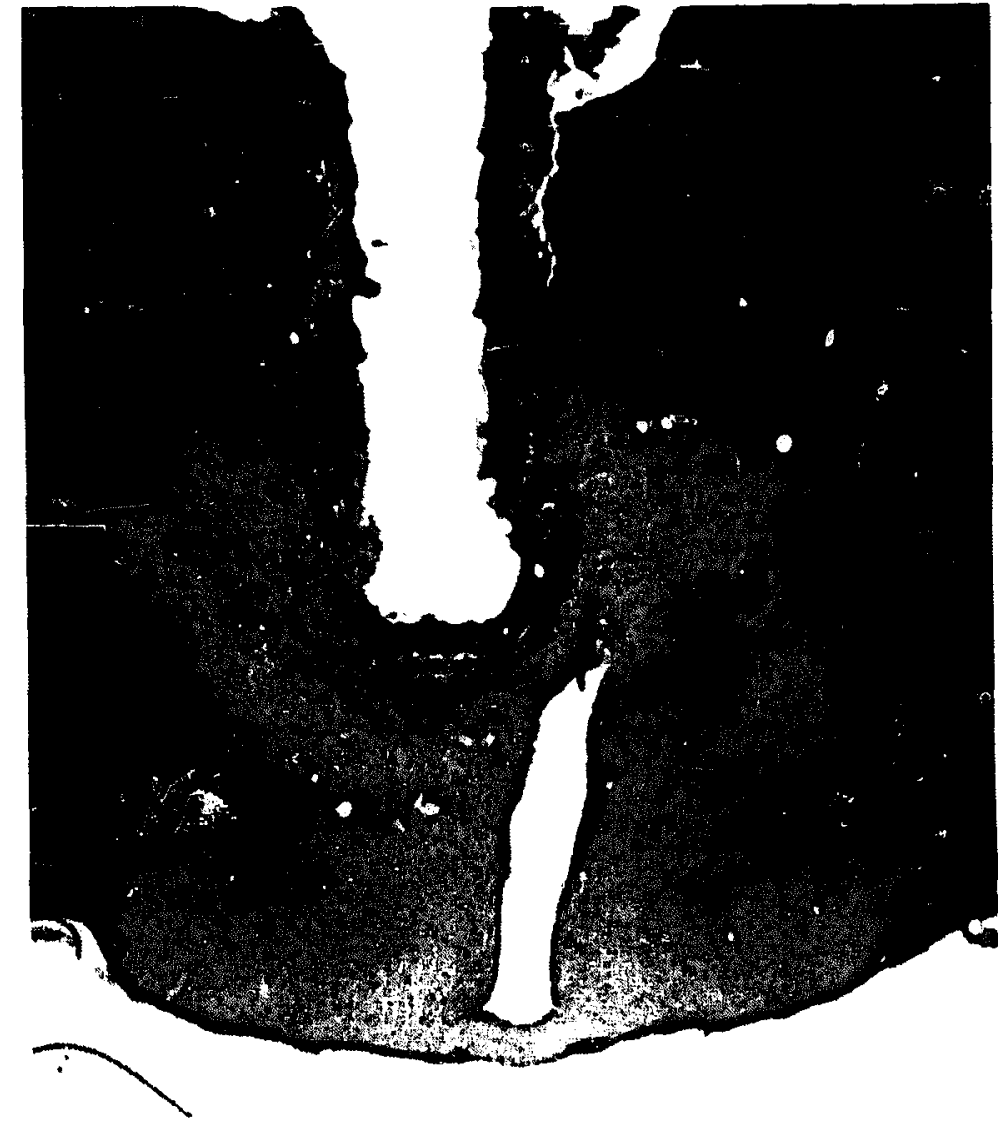

Fig. 5. Coronal section of a rat brain showing the tract caused by a guide cannula directed toward the PVN. The injection cannula extended $0.5 \mathrm{~mm}$ beyond the end of the guide cannula (Cresyl violet stain).

CRF and deprivation state and a significant interaction $\left(F_{1.11}=24.17,25.56\right.$ and 9.16 , respectively, all $P$ 's $<0.05)$. Observed frequency of rearing was not significantly affected by CRF or deprivation state.

The third experiment showed that CRF administered into the PVN suppressed food intake stimulated by NE (Fig. 4). ANOVA for the first and second hour data showed $F_{2.11}=20.47$ and 25.09 , respectively $(P<0.0001)$. Second hour means of cumulative food intakes were as follows: NS/NSA $=$ $1.32 \pm 0.5 \mathrm{~g} ; \mathrm{NS} / \mathrm{NE}=4.7 \pm 0.6 \mathrm{~g} ;$ and $\mathrm{CRF} / \mathrm{NE}=$ $2.5 \pm 0.5 \mathrm{~g}$. PVN injections of NE significantly increased cumulative food intake at 1 and $2 \mathrm{~h}(P<$ 0.05 ), and animals ate significantly less in the CRF/NE condition than in the NS/NE condition at both time points $(P<0.05)$. Results of the single botthe taste aversion test showed that the 7 animals given CRF injections drank $16.2 \pm 1.5 \mathrm{ml}$ of saccharin solution on day 1 and $20.6 \pm 1.5 \mathrm{ml}$ on re-exposure. The 5 rats given saline injections on day 1 drank $14.4 \pm 1.7$ $\mathrm{ml}$ and $15.5 \pm 4.4 \mathrm{ml}$ on re-exposure. Thus, both sets of rats showed an increase on re-exposure. A $t$-test (independent groups) comparing intake of the CRF- treated rats vs saline-treated rats on the re-exposure day showed $t=0.39$, n.s.

Fig. 5 shows the cannula tract caused by a guide cannula directed toward the PVN. The injection cannula extended $0.5 \mathrm{~mm}$ beyond the end of the guide cannula.

\section{DISCUSSION}

CRF has been shown to have potent behavioral effects (including decreasing food intake and increasing grooming) when administered i.c.v. ${ }^{4.14 .20}$. These effects are independent of its role in the hypothalamic-pituitazy-adrenal axis ${ }^{14}$. It also has been shown to have a wide intra- and extrahypothalamic distribution ${ }^{17}$. Because of these findings, we measured the amount of food eaten by food-deprived rats after receiving either CRF or saline in a local, intracerebral injection into one of 5 brain sites including the PVN, LH, VMH, GP or S. CRF caused a significant reduction of food intake when administered into the $P \vee N$ but not when administered into the other 4 sites. Reasons for this specificity of effect of exogenous CRF are not immediately apparent from reports on the distributions of CRF and CRF receptors. As determined by radioimmunoassay, Palkovits et al. ${ }^{17}$ reported the CRF concentrations (in $\mathrm{ng} / \mathrm{mg}$ protein) in these 5 areas as follows: PVN, $0.65 \pm 0.08 ; \mathrm{LH}, 0.46$ \pm 0.04 ; VMH, $0.31 \pm 0.15 ; \mathrm{GP},<0.3$; and $\mathrm{S},<0.3$. DeSouza et al. ${ }^{5}$ reported the specific binding of ${ }^{125} \mathrm{I}$ [ $\mathrm{Tyr}^{32}$ ]oCRF (in fmol/mg protein) in these nuclei as follows: PVN, $32.9 \pm 1.6$; $\mathrm{LH}, 24.0 \pm 4.8$; medial hypothalamus, $24.5 \pm 4.5 ; \mathrm{GP}, 16.5 \pm 0.5$; and $S, 47.2$ \pm 3.7. Thus, while CRF concentration and CRF binding is high in the PVN, CRF and CRF receptors are by no means found exclusively in the PVN and these distributions cannot explain the specificity we found in behavioral response. Therefore, specific connections of the PVN may provide clues to the specificity of the hehavioral response. While the PVN is intimately connected with the median eminence, it is unlikely that this is the specific outflow tract of importance since i.c.v. administration of CRF causes its anorectic and grooming effects in hypophysectomized animals ${ }^{14}$. However, the anorectic effects of i.c.v. CRF are attenuated in rats with demedullated adrenal glands ${ }^{7}$, which suggests the important participation of autonomic nervous system 
arousal in this behavioral effect. The present results suggest that the PVN may be the site of maximal anorectic response to CRF because of its powerful effects on autonomic function. Future studies on the effects of CRF administered in the PVN in animals with various lesions affecting autonomic nervous system function may be helpful in clarifying this issue.

The second set of experiments demonstrated that PVN injections of exegenous CRF cause the entire behavioral syndrome (i.e. decreased eating, increased grooming, increased movement) that is induced by exogenous CRF administered i.c.v., where it is presumably more diffusely distributed. Whether injection of CRF into other brain nuclei could elicit only part of this behavioral syndrome (e.g. increased grooming without decreased feeding) remains to be tested. Interestingly, the increases noted in grooming and movement after CRF was injected into the PVN were not significantly affected by the length of preceding food deprivation. These results suggest that the CRF-induced grooming is not simply part of the natural satiety sequence described by Antin et al. ${ }^{1}$. If it were part of a satiety sequence one would expect changes in level of hunger (i.e. length of prior food deprivation) to afiect the magnitude of the CRF-induced grooming response ${ }^{3}$. This did not occur.

NE stimulates feeding in sated rats when delivered into the PVN, and lesions of the PVN inhibit NE-induced feeding ${ }^{11}$. As we showed in the first experiment, CRF inhibits feeding induced by starvation when delivered into the PVN. CRF (i.c.v.) has been shown to inhibit the feeding induced by NE (i.c.v.) $)^{12}$.

\section{REFERENCES}

1 Antin, J., Gibbs, J., Holt, J., Young, R.C. and Smith, G.P., Cholecystokinin elicits the complete behavioral sequence of satiety in rats, J. Comp. Physiol. Psychol., 89 (1975) 783-790.

2 Bhakthavatsalam, P. and Leibowitz, S., Alpha-2 noradrenergic feeding rhythm in paraventricular nucleus: relation to corticosterone, Am. J. Physiol, , 250 (1986) R83-R88.

3 Billington, C.J.. Levine, A.S. and Morley, J.E., Are peptides truly satiety agents? A method of testing for ne.urohumoral satiety effects, Am. J. Physiol., 245 (1983) R920-R926.

4 Britton, D.R., Koob, G.F., Rivier, F. and Vale, W., Intraventricular corticotropin-releasing factor enhances behavioral effects of novelty, Life Sci., 31 (1982) 363-367.

5 DeSouza, E.B., Insel, T.R., Perrin, M.H., Rivier, J., Vale, W.W. and Kuhar, M.J., Corticotropin-releasing factor re-
We extended this finding further to show that this interaction is the same at the local level. This type of interaction of two exogenously administered substances is of uncertain physiological relevance. However, the recent findings that NE-induced feeding and PVN- $a_{2}$-receptor numbers are significantly affected by corticosterone levels in the rat suggest that the CRF and NE systems may have important physiological interactions ${ }^{2.9}$.

The failure of PVN injections of CRF to induce a conditioned taste aversion in a single bottle test stands in contrast to the previously reported findings of a taste aversion induced by CRF i.c.v. ${ }^{8}$. However, the significance of this difference in results is unclear without further testing with a wider dose range.

In summary, CRF decreased food intake when administered into the PVN but not into a numuer of other CNS areas known to be involved in food intake. This finding, along with earlier studies, suggests that the anorectic effects of CRF in the PVN may be related to its effects in autonomic arousal controlled by the PVN. PVN injections of CRF induced not only the anorectic effects but also the increased grooming and movement previously reported for rats after i.c.v. injection of CRF.

\section{ACKNOWLEDGEMENTS}

The authors wish to acknowledge the excellent technical assistance of Martha Grace and the fine clerical assistance of Jo Ann Tallman and Laurie Hall.

ceptors are widely distributed within the rat central nervous system: an autoradiographic study, J. Neurosci., 5 (1985) 3189-3203.

6 Fischman, A.J. and Moldow, R.I., Extrahypothalamic distribution of CRF-like immunoreactivity in the rat brain, Peptides, 3 (1982) 149-153.

7 Gosnell, B.A., Morley, J.E. and Levine, A.S., Adrenal modulation of the inhibitor, effect of corticotropin releasing factor on feeding. Peptides, 4 (1983) 807-812.

8 Gosnel!, B.A., Morley, J.E. and Levine, A.S., A comparison of the effects of corticotropin releasing factor and sauvagine on food intake, Pharmacol. Biochem. Behav., 19 (1983) 771-775.

9 Jhanwar-Uniyal, M., Roland, C. and Leibowitz, S., Diurnal rhythm of alpha 2-noradrenergic receptors in the paraventricular nucleus and other brain areas: relation to circulating corticosterone and feeding behavior, Life Sci., 38 (1) 466) 473-482. 
10 Joseph, S.A. and Knigge, K.M., Corticotropin-releasing factor: immunocytochemical localization in rat brain, $\mathrm{Neu}$ rosci. Lett., 35 (1983) 135-141.

11 Leibowitz, S.F., Paraventricular nucleus: a primary site mediating adrenergic stimulation of feeding and drinking, Pharmacol. Biochem. Behav., 8 (1978) 163-175.

12 Levine, A.S., Rogers, B., Kneip, J., Grace, M. and Morley, J.E., Effect of centrally administered CRF on multiple feeding paradigms, Neuropharmacology, 22 (1983) 337-339.

13 Merchenthaler, I., Vigh, S., Petrusz, P. and Schally, A.V., Immunocytochemical localization of corticotropin-releasing factor in the rat brain, Am. J. Anat., 165 (1982) 385-396.

14 Morley, J.E. and Levine, A.S., Corticotropin-releasing factor, grooming and ingestive behaviors, Life Sci., 31 (1982) 1459-1464.

15 Morley, J.E., Levine, A.S., Gosnell, B.A., Billington, C.J. and Krahn, D.D., Control of food intake. In E.E. Muller, R.M. MarLeod and L.A. Frohman (Eds.), Neuroendocrine Perspectives, Vol. 4, Elsevier, Amsterdam, 1985, pp. 145-190.

16 Olschowka, J.A., O’Donohue, T.L., Mueller, G.P. and Ja- cobowitz, D.M., The distribution of corticotropin-releasing factor-like immunoreactive neurons in rat brain, Neuroendocrinology, 35 (1982) 305-308.

17 Palkovits, M., Brownstein, M.J. and Vale, W., Distribution of corticotropin-releasing facior in rat brain, Fed. Proc., 44 (1985) 215-219.

18 Pellegrino, L.J., Pellegrino, A.S. and Cushman, A.J., $A$ Stereotaxic Atlas of the Rat Brain, 2nd edn., Plenum, New York, 1979.

19 Spiess, J., Rivier, J., Rivier, C. and Vale, W., Primary structure of corticotropin-releasing factor from ovine hypothalamus, Proc. Natl. Acad. Sci. U.S.A., 78 (1981) 6517-6521.

20 Sutton, R.E., Koob, G.F., LeMoal, M., Rivier, J. and Vale, W., Corticotropin-releasing factor produces behavioral activation in rats, Nature (London), 297 (1983) 165-186.

21 Swanson, L.W., Sawchenko, P.E., Rivier, J. and Vale, W., The organization of ovine corticotropin-releasing factorimmunoreactive cells and fibers in the rat brain: an immunohistochemical study, Neuroendocrinology, 36 (1983) 165-186. 